Jurewicz Błażej, Oberska Joanna, Prusaczyk Artur, Żuk Pawel, Guzek Marika, Bogdan Magdalena. The importance of the pharmaceutical patient questionnaire from the coordinated care perspective. Journal of Education, Health and Sport. 2022;12(1):312-320. eISSN 2391-8306. DOI http://dx.doi.org/10.12775/JEHS.2022.12.01.26

https://apcz.umk.pl/JEHS/article/view/JEHS.2022.12.01.026

https://zenodo.org/record/5918869

The journal has had 40 points in Ministry of Education and Science of Poland parametric evaluation. Annex to the announcement of the Minister of Education and Science of December 21, 2021. No. 32343. Has a Journal's Unique Identifier: 201159. Scientific disciplines assigned: Physical Culture Sciences (Field of Medical sciences and health sciences); Health Sciences (Field of Medical Sciences and Health Sciences).

Punkty Ministerialne z 2019 - aktualny rok 40 punktów. Zalącznik do komunikatu Ministra Edukacji i Nauki z dnia 21 grudnia 2021 r. Lp. 32343. Posiada Unikatowy Identyfikator Czasopisma: 201159. Przypisane dyscypliny naukowe:Nauki o kulturze fizycznej (Dziedzina nauk medycznych i nauk o zdrowiu); Nauki o zdrowiu (Dziedzina nauk medycznych i nauk o zdrowiu).

(c) The Authors 2022;

This article is published with open access at Licensee Open Journal Systems of Nicolaus Copernicus University in Torun, Poland

Open Access. This article is distributed under the terms of the Creative Commons Attribution Noncommercial License which permits any noncommercial use, distribution, and reproduction in any medium, provided the original author (s) and source are credited. This is an open access article licensed under the terms of the Creative Commons Attribution Non commercial license Share alike.

(http://creativecommons.org/licenses/by-nc-sa/4.0/) which permits unrestricted, non commercial use, distribution and reproduction in any medium, provided the work is properly cited.

The authors declare that there is no conflict of interests regarding the publication of this paper.

Received: 02.01.2022. Revised: 17.01.2022. Accepted: 28.01.2022.

\title{
Istota kwestionariusza przeglądu lekowego farmaceuty z perspektywy koordynowanej opieki zdrowotnej
}

\section{The importance of the pharmaceutical patient questionnaire from the coordinated care perspective}

Błażej Jurewicz Msc, Centrum Medyczno-Diagnostyczne w Siedlcach, Medical and Diagnostic Center in Siedlce, blazej.jurewicz@centrum.med.pl

Joanna Oberska, Zakład Medycyny Społecznej i Zdrowia Publicznego, Warszawski Uniwersytet Medyczny, Department of Social Medicine and Public Health, Medical University of Warsaw, joannaoberskaa@gmail.com

Artur Prusaczyk MD, Centrum Medyczno-Diagnostyczne w Siedlcach, Medical and Diagnostic Center in Siedlce, artur.prusaczyk@centrum.med.pl

Paweł Żuk MD, Centrum Medyczno-Diagnostyczne w Siedlcach, Medical and Diagnostic Center in Siedlce, pawel.żuk@centrum.med.pl

Marika Guzek Msc, Centrum Medyczno-Diagnostyczne w Siedlcach, Medical and Diagnostic Center in Siedlce, marika.guzek@centrum.med.pl

Magdalena Bogdan PhD, Zakład Medycyny Społecznej i Zdrowia Publicznego, Warszawski Uniwersytet Medyczny, Department of Social Medicine and Public Health, Medical University of Warsaw, mbogdan@wum.edu.pl

\section{Streszczenie}

Idea opieki farmaceutycznej zakłada ścisłą współpracę farmaceuty z przedstawicielami innych profesji medycznych $\mathrm{w}$ celu objęcia pacjenta holistyczną opieka zdrowotną. Zadaniem farmaceuty jest rozpoznawanie oraz proponowanie rozwiązań $\mathrm{w}$ zakresie problemów i interakcji lekowych. Realizacji tego procesu nie byłaby możliwa bez odpowiednich narzędzi. W ramach niniejszej pracy zaprezentowano istotę $\mathrm{i}$ zakres kwestionariusza przeglądu lekowego farmaceuty. Kwestionariusz ten jest autorskim narzędziem stworzonym w oparciu o doświadczenie i praktykę medyczno-biznesową podmiotu leczniczego Centrum Medyczno- 
Diagnostyczne w Siedlcach.

Kwestionariusz przeglądu lekowego farmaceuty umożliwia zbieranie następujących informacji: dane osobowe pacjenta, subiektywne odczucia pacjenta dotyczące jego stanu zdrowia, informacje o chorobach, alergiach, szczepieniach, badaniach okresowych i prewencyjnych oraz inne dodatkowe dane medyczne. Istotną częścią kwestionariusza jest blok informacji dot. farmakoterapii, w tym rodzaju i typie leków przyjmowanych przez pacjenta, dawkowaniu, efektywności terapii, działaniach niepożądanych związanych $\mathrm{z}$ przyjmowaniem produktów leczniczych oraz zasobach lekowych pacjenta. Prezentowane narzędzie zawiera także dodatkowe informacje bazujące na wywiadzie $\mathrm{z}$ pacjentem oraz odpowiednie zalecenia farmaceuty.

Prawidłowa identyfikacja oraz poszerzenie zakresu informacji zawartych $w$ ramach kwestionariusza przeglądu lekowego farmaceuty ma kluczowe znaczenie dla implementacji oraz realizacji koordynowanej opieki zdrowotnej, uwzgledniającej aspekt opieki farmaceutycznej.

Slowa kluczowe: opieka farmaceutyczna, kwestionariusz przeglądu lekowego farmaceuty, koordynowana opieka zdrowotna

\begin{abstract}
In the pharmaceutical care the pharmacist cooperates with other representatives of the medical professions and caters the patient with holistic care. The pharmacist concentrates on identifying and solving drug problems. The tool that makes the process feasible is the pharmaceutical patient questionnaire. Introducing this pharmaceutical patient questionnaire is the main goal of the paper.

This research investigates the issue of defining and creating pharmaceutical patient questionnaire, which can be used in coordinated pharmaceutical care process. The paper shows an original concept created by Medical and Diagnostical Center in Siedlce, Poland (MCD).

In the research and analysis process the authors of the study have created an original concept of pharmaceutical patient questionnaire, which can be used in coordinated pharmaceutical care process in Poland. The pharmaceutical patient questionnaire comprises the following information: patient's personal data, patient's subjective feelings concerning his health, different illnesses, allergies, vaccinations, preventive medical examinations and other basic medical indicators or parameters. At the core of the pharmaceutical patient questionnaire is the information on the type of medicine used taken by the patient, the name of the medicine, the doses, effectiveness of the therapy, side effects and own patient's medicine supplies. This tool also comprises information on pharmacist- patient interview, the pharmacist's recommendation and other concerning information.

Identification and reinforcement of the scope of information provided in the frame of pharmaceutical patient questionnaire may have a crucial influence on implementing and conducting coordinated pharmaceutical care.
\end{abstract}

Keywords: pharmaceutical care, pharmaceutical patient questionnaire, coordinated care

\title{
Wprowadzenie
}

Opieka koordynowana jest wymieniana jako jeden $\mathrm{z}$ najważniejszych elementów warunkujących istnienie wysoko funkcjonującej opieki zdrowotnej przynoszącej dużą wartość [1-3]. Jak pokazują wyniki badań, koordynacja maksymalizuje wartość usług świadczonych na rzecz pacjentów poprzez ułatwienie korzystania ze skutecznych, bezpiecznych i wysokiej jakości świadczeń oraz poprawę wyników opieki zdrowotnej [4]. Dzięki koordynacji opieki 
wykonywane świadczenia występują w odpowiedniej kolejności, a pacjent jest prowadzony w ramach określonego schematu podstępowania.

W celu skoordynowania pełnego procesu leczenia konieczna jest współpraca nie tylko podmiotów leczniczych, ale także innych interesariuszy. Ułatwić to może wprowadzenie Podstawowego Zabezpieczenia Zdrowotnego (PZZ), które ma polegać na współpracy i wymianie informacji pomiędzy podmiotami wchodzącymi w skład podstawowej opieki zdrowotnej (POZ), ambulatoryjnej opieki specjalistycznej (AOS) oraz szpitali pierwszego poziomu podstawowego zabezpieczenia szpitalnego [5].

Jak pokazują doświadczenia wielu krajów takich jak Stany Zjednoczone, Niderlandy czy Wielka Brytania w skuteczny proces koordynacji opieki zdrowotnej powinni zostać włączeni także farmaceuci [6-8]. Efektami opieki świadczonej przez farmaceutów jest poprawa wyników leczenia i wzrost przestrzegania zaleceń terapeutycznych $[9,10]$.

Uchwalenie ustawy o zawodzie farmaceuty w Polsce oraz informacje o planowanym pilotażu opieki farmaceutycznej wprowadzają realną możliwość rozszerzenia kompetencji farmaceutów i włączenia ich w świadczenie opieki koordynowanej w naszym kraju. Najważniejszymi zmianami wywołanymi przez ustawę, która weszła w życie 16 kwietnia 2021 roku, jest nadanie farmaceutom prawa do świadczenia usług farmaceutycznych w ramach opieki farmaceutycznej oraz zapewnienie niezależności i samodzielności farmaceutów w wykonywanych obowiązkach. W tekście ustawy opieka farmaceutyczna definiowana jest ,jako świadczenie zdrowotne stanowiace dokumentowany proces, $w$ którym farmaceuta wspótpracuje $z$ lekarzem $i$ pacjentem $i$ czuwa nad przebiegiem farmakoterapii”[11].

Podstawowym elementem opieki farmaceutycznej jest przegląd lekowy. Polega on na kompleksowej ocenie wszystkich przyjmowanych przez pacjenta leków, a jego celem jest identyfikacja i rozwiązanie problemów z nimi związanych. Przeglądy lekowe wpływają pozytywnie na wzrost stosowania zaleceń lekarskich, poprawę wyników klinicznych pacjentów oraz jakości życia, a także przyczyniają się do oszczędności w systemie ochrony zdrowia [12].

\section{Cel i metodyka badawcza}

Celem niniejszej pracy była prezentacja autorskiego kwestionariusza przeglądu lekowego farmaceuty, stanowiącego podstawowy dokument $\mathrm{w}$ procesie opieki farmaceutycznej. W ramach artykułu dokonano także oceny istoty kwestionariusza w procesie skoordynowanej opieki nad pacjentem.

Metodologia badawcza została oparta o analizę dostępnej literatury przedmiotu oraz analizę dostępnych zagranicznych, standaryzowanych narzędzi do przeprowadzania przeglądu lekowego. Identyfikację publikacji dotyczących kwestionariusza przeglądu lekowego oraz jego znaczenia w procesie opieki farmaceutycznej przeprowadzono $\mathrm{z}$ użyciem słów kluczowych: medicine review, medicne use review, medication review, pharmacy, pharmacists $\mathrm{w}$ dwóch elektronicznych bazach danych (PubMed i Scopus). Ostatnie wyszukiwanie przeprowadzone w dniu 20.06.2021. Wykluczone zostały artykuły w językach innych niż polski i angielski, opublikowane na ponad 5 lat przed wyszukiwaniem. Ponadto dokonano przeglądu piśmiennictwa analizowanych artykułów w celu zidentyfikowania dodatkowych badań lub raportów, które nie zostały odnalezione w wyniku wstępnego 
wyszukiwania. W sumie zidentyfikowano 63 artykuły, z których wybrano 5 do analizy.

Kwestionariusz został przygotowany $\mathrm{w}$ oparciu o konsultacje wewnętrzne $\mathrm{w}$ podmiocie leczniczym Centrum Medyczno-Diagnostycznym w Siedlcach, na podstawie narzędzi zidentyfikowanych $\mathrm{w}$ czasie analizy przedmiotu oraz na podstawie standaryzowanego narzędzia „Polypharmacy Guidance. Realistic Prescribing. Scottish Government Polypharmacy Model of Care Group (2018)" [13].

\section{Kwestionariusz przeglądu lekowego farmaceuty - propozycja autorskiego narzędzia}

Kwestionariusz przeglądu lekowego przygotowany w Centrum Medyczno-Diagnostycznym w Siedlcach został podzielony na 4 części dotyczące kolejno: danych medycznych pacjenta, przyjmowanych leków, wywiadu uzupełniającego oraz sugerowanych zaleceń.

Pierwsza część kwestionariusza zawiera podstawowe informacje o pacjencie, u którego wykonywania jest usługa przeglądu lekowego. Są to:

- dane personalne pacjenta,

- podstawowe pomiary życiowe i antropometryczne pacjenta (wartość ciśnienia tętniczego, tętna, poziom glukozy we krwi, BMI oraz dolegliwości zgłoszone przez pacjenta lub zaobserwowane przez farmaceutę, np. obrzęki),

- choroby przewlekłe,

- alergie,

- status wykonanych obowiązkowych i zalecanych szczepień ochronnych,

- stan realizacji badań profilaktycznych.

Ta część formularza zawiera również subiektywne odczucia pacjenta dotyczące stanu jego zdrowia, co pozwala farmaceucie na zaadresowanie tych aspektów w trakcie przeglądu lekowego.

Następnie kwestionariusz uwzględnia część pozwalającą na zebranie informacji o wszystkich produktach leczniczych przyjmowanych przez pacjenta, w tym:

- lekach dostępnych na receptę (Rp),

- lekach dostępnych bez recepty lekarskiej (OTC),

- suplementach diety,

- wyrobach medycznych,

- preparatach pochodzenia naturalnego.

Kolejny obszar kwestionariusza dotyczy wywiadu uzupełniającego. W ramach konsultacji farmaceuta zbiera informacje na temat dawki, dawkowania oraz sposobu przyjmowania leku przez pacjenta. Weryfikuje także efektywność terapii przez subiektywną ocenę stanu zdrowia pacjenta. Ponadto sprawdza czy występują jakiekolwiek skutki uboczne oraz ocenia przestrzeganie zaleceń lekarskich dotyczących stosowania leków przez pacjenta.

Kwestionariusz zawiera dodatkowo miejsce na odnotowanie daty realizacji poprzedniej recepty i zasobów lekowych pacjenta, co z jednej strony może pomóc zidentyfikować czy pacjent przyjmuje leki zgodnie z przepisanym dawkowaniem, a $\mathrm{z}$ drugiej może służyć do komunikacji z lekarzem $\mathrm{w}$ celu wystawienia kolejnej recepty lub wystawienia recepty kontynuowanej przez farmaceutę w momencie, gdy ustawodawca zezwoli na tą możliwość.

W wywiadzie uzupełniającym farmaceuta weryfikuje, czy pacjent stosuje następujące formy samokontroli: 
- czy posiada odpowiednie urządzenia, takie jak glukometr czy aparat do mierzenia ciśnienia,

- w jaki sposób przeprowadza badania samokontrole,

- czy ma zalecenia dotyczące diety, aktywności fizycznej lub stylu życia (np. palenia papierosów) i czy się do nich stosuje?

W kwestionariuszu przewidziano także miejsce na ocenę obciążenia pacjenta terapią związaną z ponoszonymi przez niego kosztami, częstotliwością badań laboratoryjnych lub wizyt lekarskich, a także stosowaniem się do dodatkowych zaleceń lekarskich. Ponadto farmaceuta ma miejsce na odnotowanie informacji, czy pacjent potrzebuje dodatkowych środków pomocowych (np. pieluchomajtek, środków ortopedycznych). Kwestionariusz weryfikuje także kiedy odbywa się kolejna wizyta kontrolna u lekarza.

W ostatniej części kwestionariusza znajduje się opis wszystkich zidentyfikowanych problemów lekowych u pacjenta. Zostały one podzielone na:

- pacjent przyjmuje zbędne leki,

- przyjmowane leki nie są zgodne z najnowszymi zaleceniami,

- terapia nie jest efektywna,

- występują interakcje międzylekowe,

- przyjmowane leki powodują silne efekty uboczne.

Następnie do każdego z problemów lekowych farmaceuta może dopisać zalecenie oraz osobę, do której jest ono adresowane. Przykładowo zmiana farmakoterapii będzie wymagała autoryzacji i konsultacji lekarza, a konsultacja dietetyczna - dietetyka. Wtedy ostatnia strona raportu staje się punktem wyjścia do komunikacji między różnymi profesjami, a kolumna $\mathrm{z}$ autoryzacją i uwagami to miejsce na kontynuowanie tej komunikacji. Szczególnie ten obszar opisywanego narzędzia, jakim jest kwestionariusz przeglądu lekowego wskazuje na praktyczny aspekt koordynacji opieki pomiędzy farmaceutą, lekarzem i pacjentem, $\mathrm{z}$ wykorzystaniem systemu IT.

\section{Podsumowanie}

Podsumowując należy podkreślić, iż realizacja opieki farmaceutycznej nie byłaby możliwa bez odpowiedniego narzędzia. W pracy przedstawiono autorski kwestionariusz przeglądy lekowego farmaceuty opracowany w oparciu o doświadczenia i praktykę medyczną podmiotu leczniczego Centrum Medyczno-Diagnostycznego w Siedlcach. Zaprezentowany kwestionariusz został nie tylko opracowany, ale także przetestowany w ramach pilotażu wdrażania opieki farmaceutycznej w CMD.

Wyniki przeprowadzonej analizy $\mathrm{w}$ zakresie istoty $\mathrm{i}$ funkcji kwestionariusza przeglądu lekowego jasno wskazują na jego ważną rolę, jaką pełni on w procesie opieki farmaceutycznej. Jest on niezbędny nie tylko do przeprowadzenie interwencji farmaceutycznej, ale także, a może przede wszystkim do pełnej realizacji procesu skoordynowanej opieki nad pacjentem. Jak pokazują wyniki badań, pełna koordynacja, uwzględniająca także opiekę farmaceutyczną, maksymalizuje wartość usług świadczonych na rzecz pacjentów poprzez ułatwienie korzystania ze skutecznych, bezpiecznych i wysokiej jakości świadczeń oraz poprawę wyników opieki zdrowotnej. Ponadto wykonywane świadczenia, w tym farmaceutyczne występują w odpowiedniej kolejności, a pacjent jest prowadzony w ramach określonego schematu podstępowania. Kolejnym atutem włączenia opieki farmaceutycznej do pełnego spectrum działań skoordynowanych jest właściwy podział 
zadań realizowanych przez poszczególnych specjalistów sektora medycznego, w tym odciążenie lekarzy i przeniesienie części uprawnień na farmaceutów. $Z$ właściwą redystrybucją zadań silnie wiąże się także kooperacja personelu medycznego i farmaceutycznego, skutkująca wzajemnym uzupełnianiem się i tym samym oferowaniem pełnej opieki medycznej i okołomedycznej pacjentom.

\title{
Załączniki
}

1. Załącznik 1 - Kwestionariusz przeglądu lekowego farmaceuty

\section{KARTA PRZEGLĄDU LEKOWEGO FARMACEUTY}

\author{
DANE PERSONALNE
}

SUBIEKTYWNE ODCZUCIA PACJENTA DOT. STANU ZDROWIA

CHOROBY PRZEWLEKLE

\section{ALERGIE}

WYKONANE SZCZEPIENIA OBOWIĄZKOWE I ZALECANE

REALIZACJA BADAŃ PROFILAKTYCZNYCH (ewentualna kwalifikacja na badania)

PODSTAWOWE POMIARY ZYCIOWE I ANTROPOMETRYCZNE PACJENTA

\begin{tabular}{|l|l|l|l|l|}
\hline $\begin{array}{c}\text { Ciśnienie } \\
\text { tętnicze }\end{array}$ & Tętno & $\begin{array}{c}\text { Glukoza } \\
\text { (pomiar } \\
\text { glukometrem) }\end{array}$ & BMI & Inne (np. obrzęki) \\
\hline Wynik & Wynik & Wynik & Wynik & Wynik \\
\hline
\end{tabular}

PRZYJMOWANE LEKI (w tym OTC (zlecone przez lekarza i przyjmowane indywidualnie))

\begin{tabular}{|c|c|c|c|c|c|c|c|c|c|}
\hline $\begin{array}{l}\text { Nazwa } \\
\text { leku }\end{array}$ & Dawka & $\begin{array}{l}\text { Dawko } \\
\text { wanie } \\
(R-P- \\
W, 1-0- \\
1 ; \\
\text { sposób } \\
\text { podani } \\
\text { a) }\end{array}$ & $\begin{array}{l}\text { Wskazani } \\
\text { e } \\
\text { (Czy } \\
\text { pacjent } \\
\text { zna } \\
\text { działanie } \\
\text { przyjmow } \\
\text { anych } \\
\text { leków?) }\end{array}$ & $\begin{array}{l}\text { Efektywnoś } \\
\text { ć terapii }\end{array}$ & $\begin{array}{l}\text { Weryfikacja czy } \\
\text { pacjent przyjmuje } \\
\text { niniejsze leki we } \\
\text { właściwy sposób } \\
\text { (Niektórzy pacjenci } \\
\text { nie przyjmuja } \\
\text { wszystkich leków z } \\
\text { różnych powodów) }\end{array}$ & $\begin{array}{l}\text { Stosowanie się do } \\
\text { zaleceń } \\
\text { (odstawione leki) }\end{array}$ & $\begin{array}{l}\text { Skutki } \\
\text { uboczne }\end{array}$ & $\begin{array}{l}\text { Data } \\
\text { realiz } \\
\text { acji } \\
\text { poprz } \\
\text { edniej } \\
\text { recept } \\
\text { y }\end{array}$ & $\begin{array}{l}\text { Zasob } \\
\text { y } \\
\text { lekow } \\
\text { e } \\
\text { pacje } \\
\text { nta }\end{array}$ \\
\hline & & $\begin{array}{l}\text { Jak } \\
\text { przyjm } \\
\text { uje }\end{array}$ & $\begin{array}{l}\text { - } C z y \\
\text { wie } \\
\text { Pan/i }\end{array}$ & 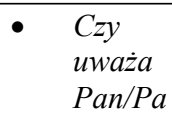 & $\begin{array}{l}\text { - } \quad \text { czy ma } \\
\text { Pan/Pani } \\
\text { jakieś }\end{array}$ & $\begin{array}{l}\text { - } \quad \text { Czy odstawił/a } \\
\text { Pan/i } \\
\text { niedawno jakiśs }\end{array}$ & $\begin{array}{l}\text { - Jak } \\
\text { Pan/i } \\
\text { czuje }\end{array}$ & & \\
\hline
\end{tabular}




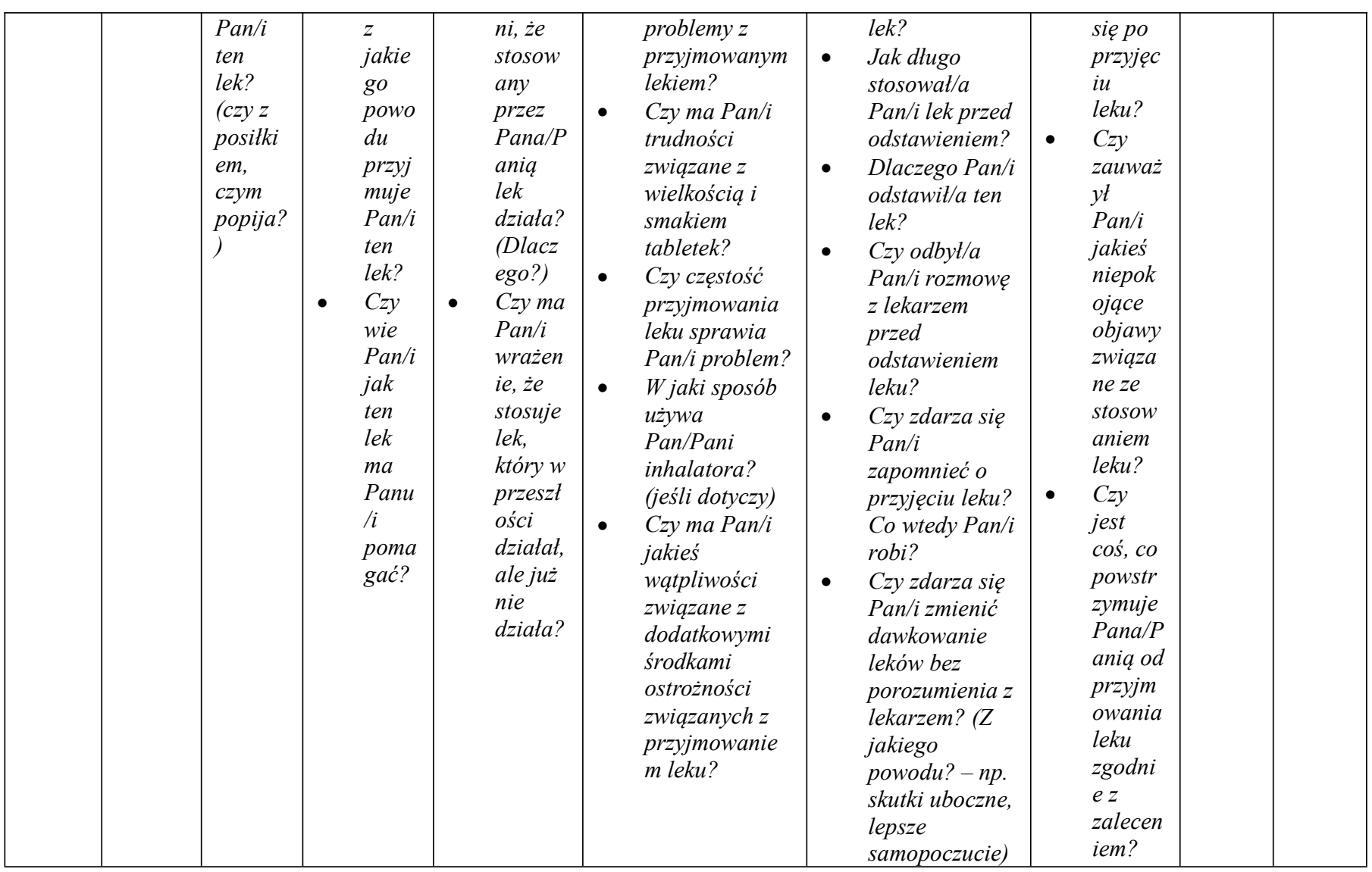

WYWIAD UZUPELNIAJĄCY

\begin{tabular}{|c|c|}
\hline $\begin{array}{l}\text { Jak pacjent ocenia swoje } \\
\text { samopoczucie? }\end{array}$ & Np. skala $1-100$ \\
\hline Stosowanie się pacjenta do zaleceń & $\begin{array}{l}\text { - Czy pamięta Pan/i o regularnym przyjmowaniu leków? Czy zdaża } \\
\text { się Panu/i zapomnieć o przyjęciu leku? } \\
\text { - Czy stosuje Pan/i pudełko na leki, napisy na pudełkach? }\end{array}$ \\
\hline $\begin{array}{l}\text { Jaka formę samokontroli prowadzi } \\
\text { pacjent? }\end{array}$ & $\begin{array}{l}\text { - Czy posiada Pan/i odpowiednie urzadzenia do samokontroli (np. } \\
\text { aparat RR, glukometr)? } \\
\text { - W jaki sposób przeprowadza Pan/i badania samokontrolne? } \\
\text { - Czy ma Pan/i zalecenia dot. diety czy aktywności fizycznej? } \\
\text { - Czy ma Pan/i zalecenia dot. dodatkowych badań } \\
\text { - Samokontrolnych? } \\
\text { - Czy ma Pan/i trudności z przestrzeganiem zaleceń dot. diety, } \\
\text { aktywości fizycznej, badań samokontrolnych? }\end{array}$ \\
\hline Obciążenie pacjenta terapią & $\begin{array}{l}\text { - Jak ocenia Pan/i swoje trudności zwiazane z terapia? } \\
\text { - Czy stosowanie się do dodatkowych zaleceń (np. nieprowadzenie } \\
\text { - } \quad \text { Cojazdów, dieta, aktywność fizyczna) sprawia Panu/i trudność? } \\
\quad \text { laboratoryjnych jest dla Pana/i częstotliwość badań } \\
\end{array}$ \\
\hline $\begin{array}{l}\text { Czy pacjent ma zastrzeżenia } \\
\text { odnośnie kosztów terapii? }\end{array}$ & - Czy koszty farmakoterapii sprawiaja Panu/Pani problem? \\
\hline
\end{tabular}




\begin{tabular}{|l|l|}
\hline $\begin{array}{l}\text { Czy pacjent potrzebuje } \\
\text { dodatkowych środków } \\
\text { pomocowych? }\end{array}$ & $\bullet$ Pieluchomajtki \\
\hline $\begin{array}{l}\text { Na kiedy pacjent ma umówioną } \\
\text { kolejna wizytę u lekarza? }\end{array}$ & \\
\hline $\begin{array}{l}\text { Czy pacjent ma dodatkowe pytania } \\
\text { dotyczące przyjmowanych leków? }\end{array}$ & \\
\hline
\end{tabular}

\section{ZALECENIA}

\begin{tabular}{|c|c|c|c|}
\hline Zidentyfikowany problem lekowy & Zalecenie & $\begin{array}{l}\text { Do kogo } \\
\text { zaadresowane jest } \\
\text { zalecenie? }\end{array}$ & $\begin{array}{l}\text { Autoryzacja } \\
\text { zalecenia, } \\
\text { uwagi }\end{array}$ \\
\hline $\begin{array}{l}\text { - pacjent przyjmuje zbędne leki (jakie?) - Dlaczego } \\
\text { pacjent przyjmuje dany lek? Czy wynika to z historii } \\
\text { choroby? Co statoby się, gdyby lek zostat } \\
\text { odstawiony? Czy można zaproponować prostszy } \\
\text { schemat farmakoterapii lub terapię } \\
\text { niefarmakologiczna? } \\
\text { przyjmowane leki nie sa zgodne z najnowszymi } \\
\text { zaleceniami - Czy zalecenia EBM zmienity się od } \\
\text { czasu zainicjowania terapii? Czy pacjent przyjmuje } \\
\text { leki w odpowiedniej dawce? } \\
\text { terapia nie jest efektywna (dlaczego?) - Wyniki } \\
\text { pacjenta (ciśnienie tętnicze, stężenie } \\
\text { glukozy/cholesterolu) nie sq satysfakcjonujace z } \\
\text { punktu widzenia efektywności terapii. Czy któraś z } \\
\text { chorób pacjenta nie jest leczona optymalnie? Czy } \\
\text { pacjent zgłasza dodatkowe problemy, które nie sa } \\
\text { rozwiazane przez aktualna farmakoterapię? } \\
\text { wystepuja interakcje międzylekowe (jakie?) Czy } \\
\text { stosowane leki sq przeciwskazane u pacjenta? } \\
\text { przyjmowane leki powoduja silne efekty uboczne } \\
\text { (jakie?) - Czy pacjent stosuje dodatkowe leki lub } \\
\text { preparaty, które moga spowodować interakcje lub sq } \\
\text { przeciwskazane? Czy pacjent przyjmuje leki, których } \\
\text { zadaniem jest ograniczenie skutków ubocznych (np. } \\
\text { IPP przy NLZP) i czy stosowanie leków wywotujacych } \\
\text { skutki uboczne nie powinno być rozważone ponownie? } \\
\text { Czy można wdrożyć strategie pozwalajace na lepsza } \\
\text { kontrole skutków ubocznych (zmiana dawki, leku lub } \\
\text { zmiana pory podania leku)? Edukacja pacjenta nt. } \\
\text { skutków ubocznych i dtugotrwatych efektów terapii } \\
\text { czy należy wykonać testy diagnostyczne } \\
\text { monitorujące efekty uboczne przyjmowanych leków? }\end{array}$ & & $\begin{array}{ll}\text { - } & \text { Do } \\
& \text { farmaceuty } \\
\text { - } & \text { Do pacjenta } \\
\text { - } & \text { Do lekarza } \\
\text { - } & \text { Do } \\
& \text { pielegniarki }\end{array}$ & \\
\hline
\end{tabular}

\section{DODATKOWE UWAGI}

Pieczątka i podpis farmaceuty 


\section{Piśmiennictwo}

1. Baxter S, Johnson M, Chambers D, et al. The effects of integrated care: a systematic review of UK and international evidence. BMC Health Serv Res. 2018;18(1):350.

2. Bodenheimer T, Ghorob A, Willard-Grace R, et al. The 10 building blocks of highperforming primary care. Ann Fam Med. 2014;12(2):166-71.

3. Simon M, Choudhry NK, Frankfort J, et al. Exploring Attributes of High-Value Primary Care. Ann Fam Med. 2017;15(6):529-34.

4. Forum NQ. NQF-Endorsed Definition and Framework for Measuring Care Coordination 2006 [cited: 20.01.2022]; Available from: https://www.tnaap.org/documents/nqf-definition-and-framework-for-measuring-care-co.pdf.

5. Ministerstwo Zdrowia. Strategiczne kierunki rozwoju systemu ochrony zdrowia w Polsce. Wyniki ogólnonarodowej debaty o kierunkach zmian w ochronie zdrowia. Dokument podsumowujący. [Strategic directions of health care system development in Poland. Results of a national debate on the direction of change in health care. Summary document]. Polish. 2019.

6. Freund T, Everett C, Griffiths P, et al. Skill mix, roles and remuneration in the primary care workforce: Who are the healthcare professionals in the primary care teams across the world? International Journal of Nursing Studies. 2015;52(3):727-43.

7. Hazen ACM, Sloeserwij VM, Zwart DLM, et al. Effects of non-dispensing pharmacists integrated in general practice on medication-related hospitalisations: results of the point study. Non-dispensing clinical pharmacists in general practice. 2018:159.

8. $\quad$ National Health Service England. The NHS Long Term Plan. 2019.

9. Jeong S, Lee M, Ji E. Effect of pharmaceutical care interventions on glycemic control in patients with diabetes: a systematic review and meta-analysis. Ther Clin Risk Manag. 2018;14:1813-29.

10. Milosavljevic A, Aspden T, Harrison J. Community pharmacist-led interventions and their impact on patients' medication adherence and other health outcomes: a systematic review. Int J Pharm Pract. 2018;26(5):387-97.

11. Ustawa $\mathrm{z}$ dnia 10 grudnia 2020 r. o zawodzie farmaceuty. [Polish Government. Act of December 10, 2020 on the profession of pharmacist]. Dz.U. 2021 poz. 97. Polish.

12. Jokanovic N, Tan EC, Sudhakaran S, et al. Pharmacist-led medication review in community settings: An overview of systematic reviews. Res Social Adm Pharm. 2017;13(4):661-85.

13. Scottish Government Polypharmacy Model of Care Group. Polypharmacy Guidance, Realistic Prescribing 3rd Edition, 2018. Scottish Government. 